\title{
The Repository for Caribbean Cancer Publications (ReCCaP): Database Development and Publication Trends 2004-2019
}

\author{
Kimberly Badal \\ Moesha Moore \\ Mikhail Thomas \\ Caribbean Cancer Research Initiative, \\ Port of Spain, Trinidad and Tobago
}

Correspondence: Kimberly Badal Caribbean Cancer Research Initiative, 17 Alcazar St, Port of Spain, Trinidad and Tobago

Email kimberly@ccrinitiative.com
Objective: In the Caribbean region, research has been limited, making it challenging to find. In order for the region to optimally access and utilize present research and identify gaps, we developed the Repository for Caribbean Cancer Publications (ReCCaP) to home publications on cancer in the Caribbean population and diaspora and report on publication trends.

Methods: A systematic PubMed literature search for the period 2004-2019 (15 years) was developed using keywords related to "cancer" and "Caribbean." Three independent investigators verified included publications. The final database was formatted and hosted in an online database management software. Publication trends over time, by country, cancer type, and income classification were investigated.

Results: Of the 4935 publications found, 1194 papers met the inclusion criteria with 803 publications (67.25\%) being on the Caribbean population, 139 publications $(11.64 \%)$ including multiple Caribbean countries and 252 publications $(21.11 \%)$ on the diaspora. Between 2004 and 2019, there was an overall 0.20 increase in publications regionally. Overall, most publications were on breast $(\mathrm{n}=168,14.07 \%)$, prostate $(\mathrm{n}=156,13.07 \%)$, cervical $(n=152,12.73 \%)$, colorectal $(n=80,6.70 \%)$, and lung cancer $(n=36,3.02 \%)$. The highest number of papers were published by Puerto Rico (22.80 pubs/year), Cuba (8.27 pubs/year), Jamaica (6.27 pubs/year), Trinidad and Tobago (3.53 pubs/year), and Martinique (2.27 pubs/year). The high-income countries $(n=10)$ collectively lead in publications over the 15-year period.

Conclusion: ReCCaP provides an easily searchable database highlighting published work and gaps in knowledge on cancer in the Caribbean and diaspora.

Keywords: cancer, Caribbean, West Indies, Caribbean diaspora, English-speaking Caribbean, French-speaking Caribbean, Dutch-speaking Caribbean, Spanish-speaking Caribbean, database

\section{Article Summary}

This paper highlights ReCCaP development and publication trends for cancer in the Caribbean and Caribbean diaspora over 15 years (2004-2019). The top five cancer publication topics aligned with the region's top five cancer burdens. There was an overall small 0.20 times increase in publications over time across the Caribbean region, with higher income countries publishing the most compared to lowerincome countries. ReCCaP illustrates that the Caribbean region is behind on research on cancer in its population. 


\section{Strengths and Limitations}

- This study highlights publication trends on cancer in the Caribbean and Caribbean diaspora over 15 years for the first time

- This study shows the relationship between publication rate, country, study type, population size, and income classification

- This study reports on the creation of $\mathrm{ReCCaP}$ - an easily searchable literature database

- A limitation of this study is that the systematic literature search included only the PubMed database and therefore omits articles that are not Medlineindexed

\section{Introduction}

The Caribbean region has a combined population of approximately 44 million, ${ }^{1}$ comprising 31 different political divisions, including independent and dependent territories. ${ }^{2}$ These countries and territories vary in size, geography, economic resources, culture, and language. Bermuda is the northernmost island, with Guyana and Suriname in the south, Barbados in the East, and Belize in the west. Cuba is the largest island by geography and home to a population of $11.33 \mathrm{M}$ people, while Anguilla, the smallest island, is home to $0.015 \mathrm{M}$ people. ${ }^{1}$ The majority of countries are high-income (20 countries) followed by upper-middle-income (10 countries), with the only low-income country being $\mathrm{Haiti}^{2}{ }^{2}$ Some countries rely on commodity exports such as petroleum-based products, bananas, rum, and iron ore products, while others rely solely on tourism. ${ }^{2}$ There are six main native languages found in the Caribbean: English, Spanish, Dutch, French, Creole, and Papiamento.

Cancer is the second leading cause of death worldwide. ${ }^{3}$ In 2018, there were 9.6 million deaths due to cancer, with $70 \%$ of these deaths occurring in low- and middle-income countries. ${ }^{3}$ The World Health Organization estimates that in 2020, there were 109,610 new cases and 63,862 deaths due to cancer in the Caribbean region. ${ }^{4}$ Prostate cancer is the leading cause of cancer death in Caribbean men, followed by lung cancer. ${ }^{5}$ In Caribbean women, breast cancer is the leading cause of cancer death, followed by cervical cancer. ${ }^{5}$ Cancer incidence and mortality rates differ across the region attributed to social and economic inequalities and differences in health care access. ${ }^{5}$ In 2020, Guadeloupe was estimated to have the highest age-standardized cancer incidence rate (258.6 per 100 000) and the Dominican Republic the lowest (172.4 per 100000$)$, while mortality rates were highest in Barbados (121.9 per 100 000) and lowest in Martinique (79.4 per 100000$){ }^{4}$

Research is the backbone to improving cancer prevention and management, yet in the Caribbean region, it has been limited and challenging to find with little translation into intervention $^{6-8}$ similar to trends reported in Latin America. ${ }^{9}$ The region had made efforts to increase health research capacity ${ }^{10,11}$; however, it is unknown whether these efforts have translated to an increase in publication output.

To improve publication visibility and accessibility and to monitor publication trends over time, the Caribbean Cancer Research Initiative (CCRI) developed the Repository for Caribbean Cancer Publications (ReCCaP). $\mathrm{ReCCaP}$ is a user-friendly, easily searchable online database that houses research on cancer in the Caribbean and the Caribbean diaspora. $\mathrm{ReCCaP}$ is intended as a resource for researchers, students, and secular society to easily identify what is known and gaps. In this paper, we present $\mathrm{ReCCaP}$ development and report on cancer publication trends in the Caribbean region and diaspora for 20042019. Publication trends were analyzed to determine 1) whether publication rates (PR) have increased over time; 2) the publication distribution by geography and cancer type; and 3) whether number of tertiary institutions or GDP are associated with PR.

\section{About the Caribbean Cancer Research Initiative}

Historically there has been no coordinated, well-funded research center that focuses on understanding cancer in the Caribbean. The Caribbean Cancer Research Initiative (CCRI) was established in 2016 as a not-for-profit organization with a vision to develop an innovative, internationally recognized, and self-sustained cancer research institute for the Caribbean. CCRI undertook the work of developing this database as a necessary step towards having a comprehensive understanding of the current status of cancer research in the Caribbean and in service of furthering regional research.

\section{Methods}

\section{Literature Search and Inclusion Criteria}

A PubMed query was developed in January 2020 to capture relevant articles. The search builds on a search strategy previously defined for the Latin America and Caribbean. ${ }^{12}$ Terms related to "cancer" (eg, "neoplasm", "carcinogen") were combined with terms related to 
"Caribbean" (eg "West Indies", "English Speaking Caribbean", "French-Speaking Caribbean," and "Dutchspeaking Caribbean", "Barbados", "Trinidad and Tobago", "Jamaica", "Bahamas", “Saint Marten”, "Haiti", "Guyana", "Belize", "Anguilla", “Antigua and Barbuda", "Suriname", "Saint Kitts and Nevis", "Saint Vincent and the Grenadines"). The search was limited to 15 years (January 1, 2004 to December 31, 2019). The final search string is presented in Supplementary Table 1.

The inclusion criteria for $\mathrm{ReCCaP}$ were that the publication must be on cancer in a population from the Caribbean or diaspora. The diaspora refers to populations of Caribbean origin residing outside the Caribbean region. All study types, eg, epidemiologic, interventional, and psychosocial studies and case reports were included. Publications were also included if they focused on Caribbean environmental or viral risk factors, prevention and control (includes health care, screening, registries, and biobanking), education and training, and research into active compounds from Caribbean flora or fauna. Publications were also included if they were in languages other than English once they had an English translation accompanying the text for interpretation. In vitro experiments carried out in a Caribbean-based lab that did not include use of active compounds from Caribbean flora or fauna, and publications on benign tumors were excluded.
The search results were upload to statistical software RStudio Version 1.3.959. ${ }^{13}$ The articles were split by those with cancer in the title $(n=1816)$ and those without cancer in the title $(n=3119)$ (Figure 1). Two authors (MM and MT) independently assessed if the articles met the inclusion criteria based on a review of the abstract and full text where necessary. A third author (KB) independently reviewed and finalized articles to be included (Figure 1). The final list of included articles was edited to include the title, authors, publication year, journal, cancer type, study type, and website link.

\section{Database Management Tool Selection}

We conducted an internet search for an online database management software that would be user-friendly, costeffective, had online support, and a full-access free trial. Out of 11 database management software found, we determined that the Knack* program (www.knack.com) met our criteria.

\section{Database Analysis}

Over time, the distribution of papers by country, cancer type, and income classification were summarized with frequency statistics and presented using graphed moving averages. GDP per capita and population size data were obtained from the World Bank. ${ }^{14}$ The number of tertiary

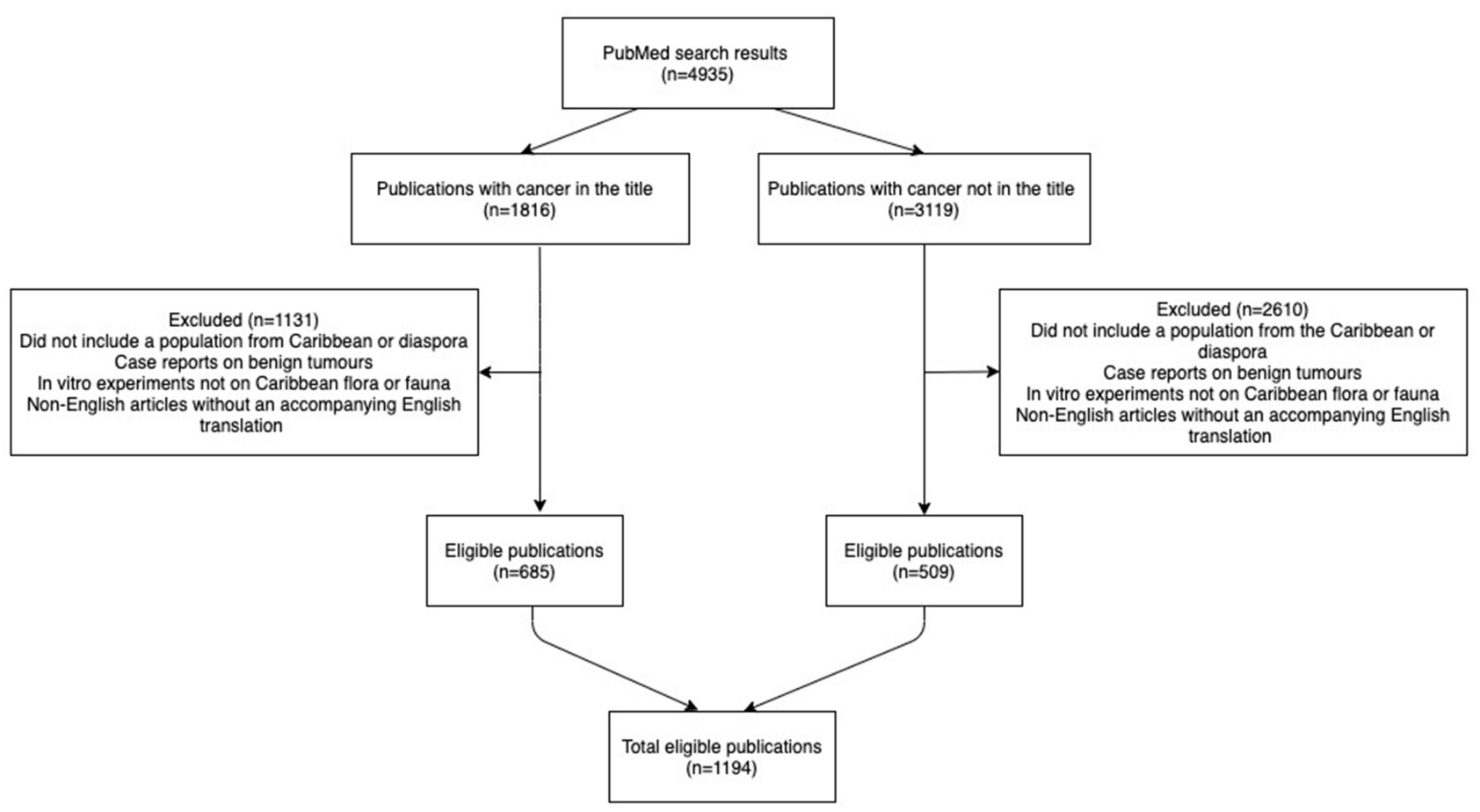

Figure I Flowchart illustrating the number of articles included and excluded based on ReCCaP selection criteria. 
education institutions per Caribbean country was obtained from UniPage. ${ }^{15}$ Maps were made using ArcGIS Online (www.arcgis.com). PR was calculated as the total number of articles divided by the database duration (15 years). Wilcoxon Rank Sum Test was used to investigate associations between PR and income classification, population size and number of universities. All analysis was completed using RStudio Version 1.3.959. ${ }^{13}$

\section{Quality Assessment}

Database exhaustiveness and ease of use were assessed by prominent authors who publish significantly in this space. We also cross-referenced the list of 102 publications from the African Caribbean Cancer Consortium (AC3), a consortium that focuses on cancer research in the Caribbean and Africa. We considered the database to be exhaustive once all cross-referencing yielded no new results.

\section{Results}

\section{Publication Distribution by Geography and Cancer Type}

Our PubMed search resulted in 4935 publications of which 1194 papers $(24.19 \%)$ met our database inclusion criteria (Figure 1) with 803 publications $(67.25 \%)$ being on the Caribbean population, 139 publications (11.64\%) including multiple Caribbean countries and 252 publications $(21.11 \%)$ on the diaspora. We investigated the distribution of publications by Caribbean country and cancer type. Puerto Rico $(n=342,28.64 \%)$ had the highest number of publications overall, followed by Cuba ( $n=124,10.39 \%)$, Jamaica $(n=94,7.87 \%)$, Trinidad and Tobago $(n=53$, $4.44 \%)$ and Martinique $(n=34,2.85 \%)$. Haiti had the sixth highest number of publications $(n=31,2.60 \%)$. Publications were most frequently on breast $(n=168$, $14.07 \%)$ followed by prostate $(n=156,13.07 \%)$, cervical $(n=152,12.73 \%)$, colorectal $(n=80,6.70 \%)$ and lung cancer $(n=35,3.02 \%)$. The most frequent publication topic was epidemiology $(n=394,33 \%)$, followed by prevention and control $(n=224,18.76 \%)$, disparities $(n=222,18.59 \%)$, treatment $(n=164,13.74 \%)$ and viral risk factors $(n=126$, $10.55 \%$ ) (Supplementary Figure 1).

For the five countries with the highest number of publications, we investigated the top five publication topics by cancer site (Figure 2). Breast and colorectal cancer were the leading publication topics for Puerto Rico $(n=39$, $27.86 \%$ ). Prostate cancer was the leading publication topic for Trinidad and Tobago $(n=14,37.84 \%)$, Jamaica $(\mathrm{n}=26,44.83 \%)$ and Martinique $(\mathrm{n}=7,38.89 \%)$. Lung cancer was the leading publication topic for Cuba $(n=18$, $39.13 \%)$. Of note, Cuba has published on leukemia $(n=5$, $10.87 \%)$, Jamaica $(n=7,12.07 \%)$ and Puerto Rico $(n=16$, $11.43 \%$ ) on head and neck cancer and Martinique on eye cancer $(\mathrm{n}=2,11.11 \%)$ (Figure 2$)$.

\section{Publication Distribution Over Time}

Figure 3 shows the moving averages of the number of publications over time. Between 2004 and 2019, there was an overall 0.20 times increase $(n=49,4.10 \%$ vs $\mathrm{n}=59,4.94 \%$ ) in publications over time across the Caribbean region with the highest number of publications in $2017(\mathrm{n}=112,9.38 \%)$ (Figure 3A). We investigated the publication distribution over time for the top five countries with the highest PRs (Figure 3B). Puerto Rico had the highest number of publications over time, with a peak in 2017 ( $n=39,34.82 \%$ ). Cuba had the second-highest number of publications over time. A continuous decline in publications was observed for Jamaica after a peak in $2012(\mathrm{n}=16,18.18 \%)$ to its lowest in $2019(\mathrm{n}=1,1.69 \%)$. Martinique had an overall 4 times increase in the number of publications between 2004 and 2019 ( $n=1,2.04 \%$ vs $\mathrm{n}=5,8.47 \%$ ). Trinidad and Tobago showed an overall 1-time increase over time from $(n=2,4.08 \%)$ in 2004 to $(\mathrm{n}=4,6.77 \%)$ in 2019 .

We also investigated the publication distribution for the top five cancer subtype topics (Figure 3C). There has been no overall increase between 2004 and 2019 for breast $(n=8$ vs $n=8$ ), a 0.11 times increase for prostate ( $n=9$ vs $n=10$ ), a 0.50 times decrease for cervical $(n=6$ vs $n=3)$, a 2 times increase for lung ( $n=0$ vs $n=2)$ and a 5 times increase for colorectal ( $n=1$ vs $n=6$ ). The publication distribution over time by country income classification is shown in Figure 3D. Overall, high-income countries had more publications at every time point over the 15 years.

\section{Publication Rate by Geography, GDP, and Number of Universities}

Overall, the Caribbean region had a 15-year PR of 79.6 pubs/year. In the lesser Antilles (Figure 4A), Trinidad and Tobago ( $\mathrm{n}=53,3.53$ pubs/year), Martinique $(\mathrm{n}=34,2.27$ pubs/year) and Guadeloupe ( $n=29,1.93$ pubs/year) had the highest 15-year PRs while Curacao ( $\mathrm{n}=2,0.13$ pubs/ year) St. Lucia ( $\mathrm{n}=1$ paper, 0.07 pubs/year) and St. Kitts and Nevis ( $\mathrm{n}=1,0.07$ pubs/year) had the lowest rates. 


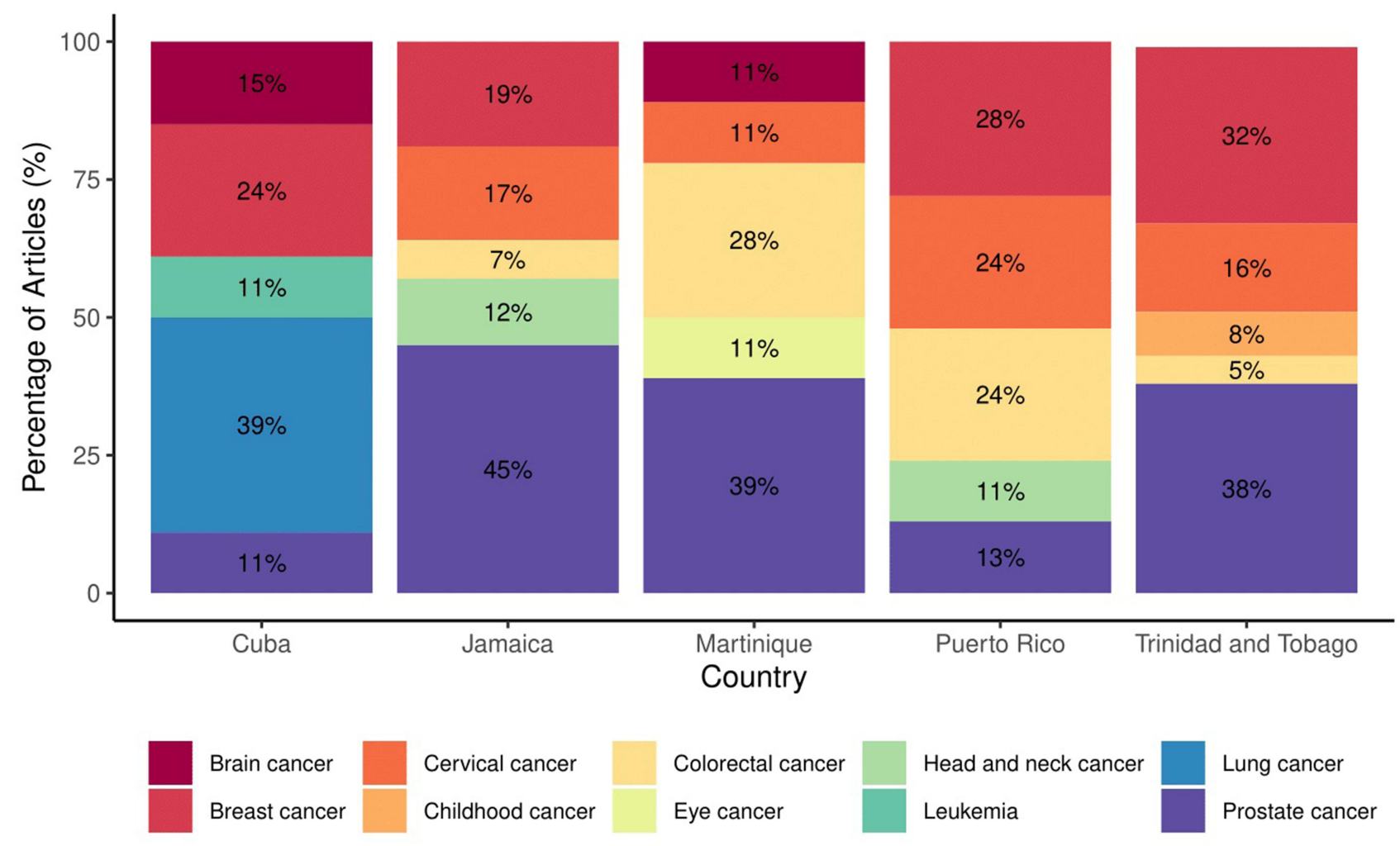

Figure 2 Stacked column graph showing the top 5 countries with the highest publication rates over the period 2004-2019 and their top 5 cancer type publication topics.

Trinidad and Tobago, Martinique, and Guadeloupe are high-income countries, with Trinidad and Tobago having three universities and Martinique and Guadeloupe having one university. St. Lucia and Curacao have one university, whereas St. Kitts and Nevis have five tertiary education institutions.

In the Greater Antilles (Figure 4B), Puerto Rico ( $\mathrm{n}=342$, $22.80 \mathrm{pubs} /$ year), $\mathrm{Cuba}(\mathrm{n}=124,8.27 \mathrm{pubs} / \mathrm{year}$ ) and Jamaica ( $\mathrm{n}=94,6.27$ pubs/year) had the highest 15-year PRs. Cayman Islands ( $\mathrm{n}=1,0.07$ pubs/year), Bermuda ( $\mathrm{n}=1,0.07$ pubs/year) and Belize ( $\mathrm{n}=2,0.13$ pubs/year) had the lowest 15 -year PR. Of note, Haiti - the only low-income Caribbean country - had the fourth highest 15-year PR across the Greater Antilles ( $n=31$, 2.07 papers/year). All the islands within the Greater Antilles have at least one university, with the Dominican Republic having the most universities/tertiary education institutions $(\mathrm{n}=28)$. In contrast, Bermuda and The Bahamas have the least number of universities/tertiary education institutions $(\mathrm{n}=1)$. Puerto Rico ( $\mathrm{n}=342,22.80$ papers/year) had the highest 15-year PR overall. No association between PR and income classification ( $p=0.81$ ) or PR and number of universities were found $(\mathrm{p}=0.79)($ Supplementary Table 2) .

\section{Country-Specific Cancer Mortality Rate and Publication Focus}

We compared the cancer type publication focus of the countries with the top five PRs with leading causes of cancer death for that country (Supplementary Table 3). In general, breast, prostate, colorectal, and lung cancer have the highest mortality rates across Puerto Rico, Cuba, Jamaica, and Trinidad and Tobago. Stomach cancer has the third highest mortality rate in Martinique ( 7.0 per 100000 ), though this has not been a publication focus for this country. Jamaica and Trinidad and Tobago focus similarly on prostate, breast, and cervical cancer publications, though colorectal cancer has the third highest mortality rate in these countries. Cuba's focus on lung cancer is in line with it being the highest mortality rate in that country. Puerto Rico's publication focus is not directly in line with its cancer burden, with fewer publications on lung and prostate cancer, the second and third highest cause of cancer death in that country.

\section{Database Use}

Figure 5 shows the ReCCaP user interface displaying the title, authors, link, journal, country cancer type, study type, 


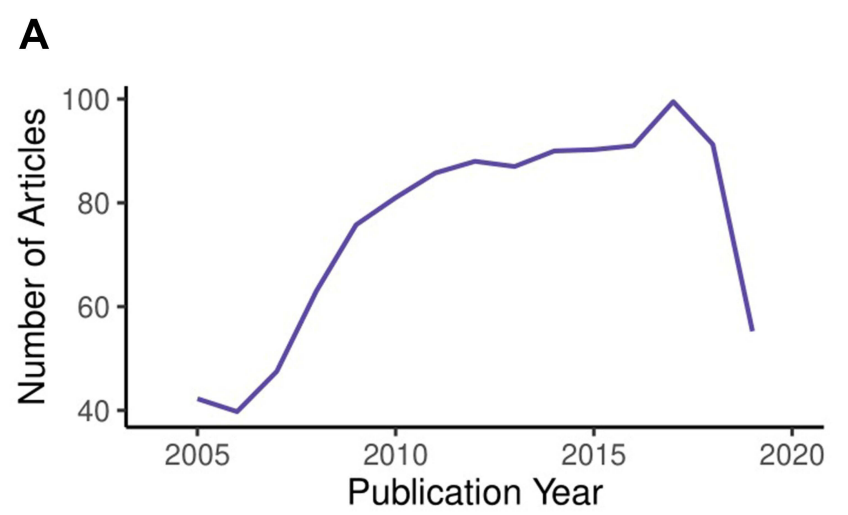

C

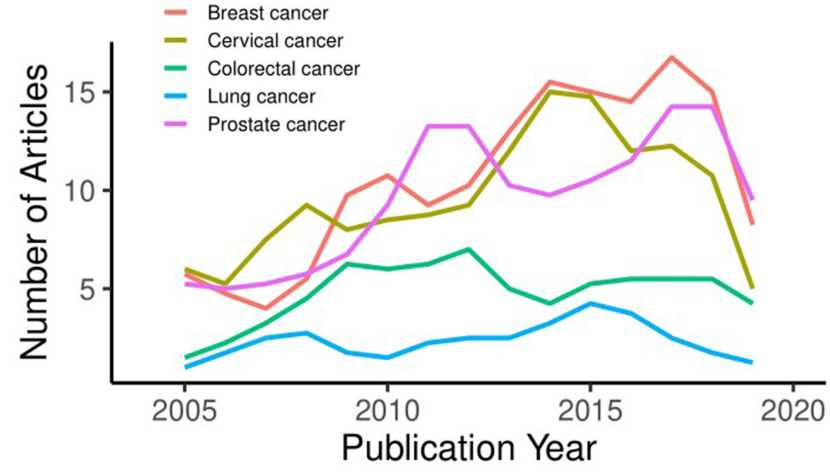

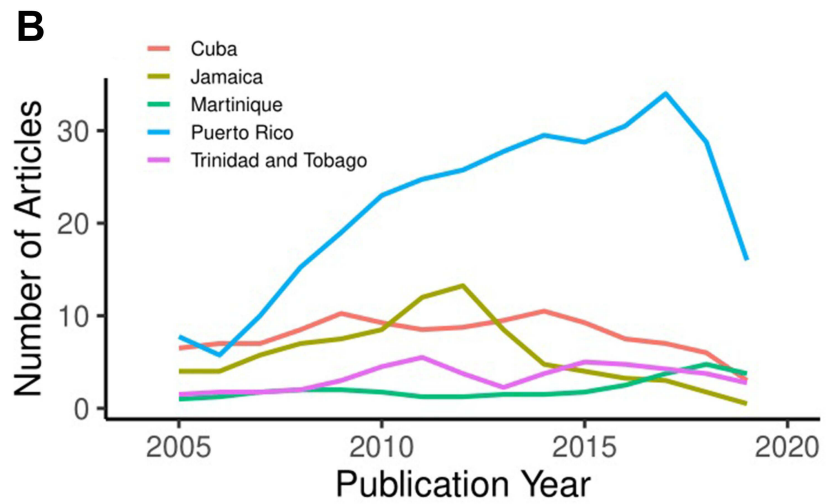

D

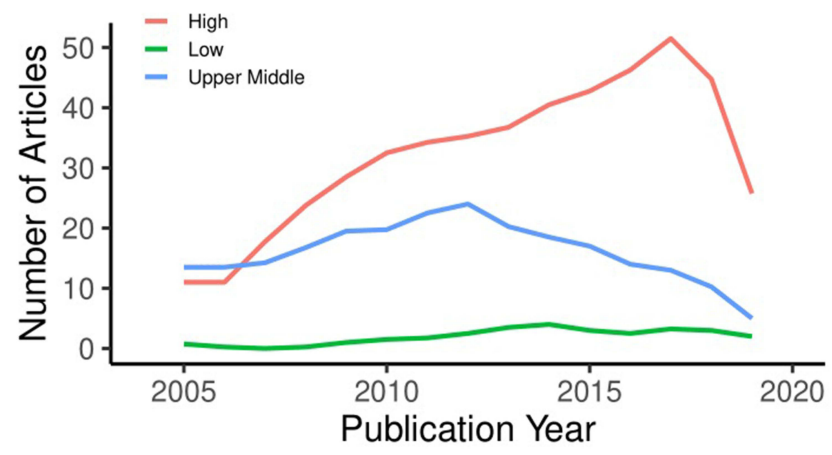

Figure 3 Moving averages of number of articles published over time for the period 2004-2019 (A) overall; (B) by top 5 countries; (C) by top 5 cancer types and (D) by income classification.

and year for each publication entry. The database allows the user to filter and search by any of the headings individually or using Boolean operators to combine terms of interest. Each publication entry is linked directly to the journal website hosting the paper.

\section{Discussion}

One key strategy needed to address the Caribbean cancer burden and improve patient outcomes is a data-driven understanding of the problem. Research on cancer in Caribbean has been historically limited and challenging to find. We developed $\mathrm{ReCCaP}$ to house all publications on cancer in the Caribbean region and diaspora and report on publication trends over time. ReCCaP allows the enduser to easily explore publications by authors, country, title, cancer type, and study type. It can also be used to determine what is known and gaps.

ReCCaP highlights a 15-year PR of 79.6 pubs/year across 30 Caribbean countries for 2004-2019. To our knowledge, cancer research PRs in other world regions have not been published. A preliminary PubMed search revealed that the United Kingdom published 63,463.20 papers/year by comparison. The United States of
America published 270,500 papers/year, Canada published 4870.53 papers/year, and India published 52,178.53 papers/year. Though these are rough estimates and these countries have larger population sizes and greater human and financial resources, it does illustrate that the Caribbean region - which has roughly the same population size as Canada - is behind on cancer research in its population.

As expected, the top five cancer publication topics aligned with the region's top five cancer burdens. ${ }^{4}$ Generally, countries with populations of more than 1 million had the highest PRs. These countries have a greater workforce, are more likely to have at least one tertiary education institution and have a higher number of cancer patients which demands attention to healthcare strategy. Martinique - a high-income country with a small population of $0.38 \mathrm{M}$ and one University - is an outlier with the fifth highest 15 -year PR in the region. It is a French territory with one tertiary education institution. Martinique demonstrates its focus on cancer research through robust data collection through the Martinique Cancer Registry and publication of results. ${ }^{16-18}$ Of note, Jamaica - an upper-middle-income country of $2.95 \mathrm{M}$ people and three universities - has the third highest PR overall 

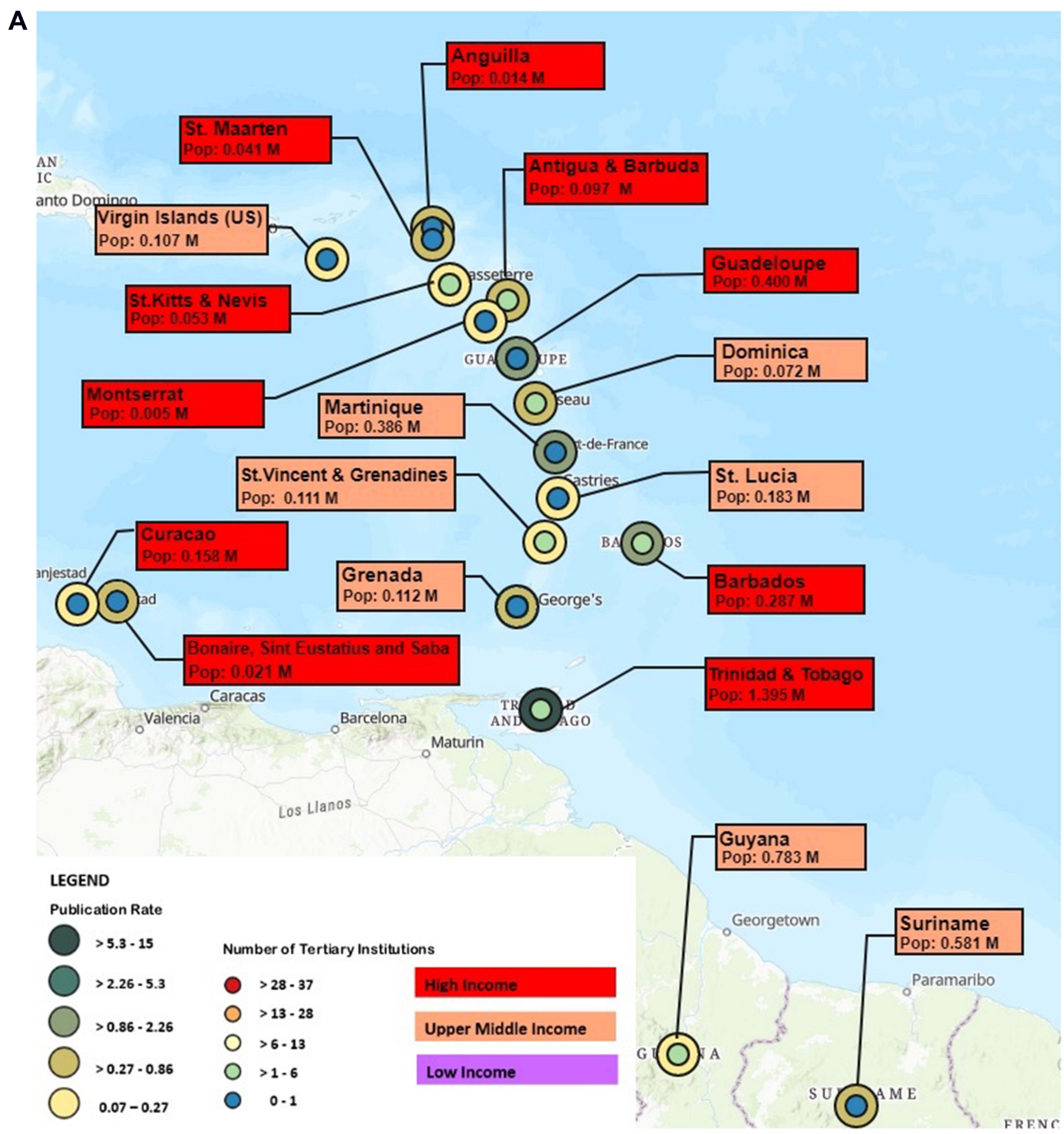

Figure 4 (A). Map showing the income classification, number of universities and publication rates for the period 2004-2019 for countries in the Lesser Antilles. White circles indicate no publications over the period. (B) Map showing the income classification, number of universities and publication rates for the period 2004-2019 for countries in the Greater Antilles.

but has experienced a steady decline since 2012. In 2012, Jamaica experienced negative economic growth $(-0.30 \%)$, with their goods and service sector declining or showing no growth. ${ }^{19}$ This decline in GDP may have impacted its ability to focus resources on research. Puerto Rico - an unincorporated U.S territory of $3.19 \mathrm{M}$ people and 26 tertiary education institutions - had the highest PR overall.
Puerto Rico's GDP per capita ( $\$ 32$ 873.72) is six times greater than Jamaica's ( $\$ 5582.26)$ and twice as great as Trinidad and Tobago (\$17 275.47). ${ }^{14}$ Like Martinique, Puerto Rico's strong international affiliation, as well as its high GDP, may explain its high PR.

Cuba - the largest island in the Caribbean by geography with a population of $11.33 \mathrm{M}$ and 13 tertiary education 


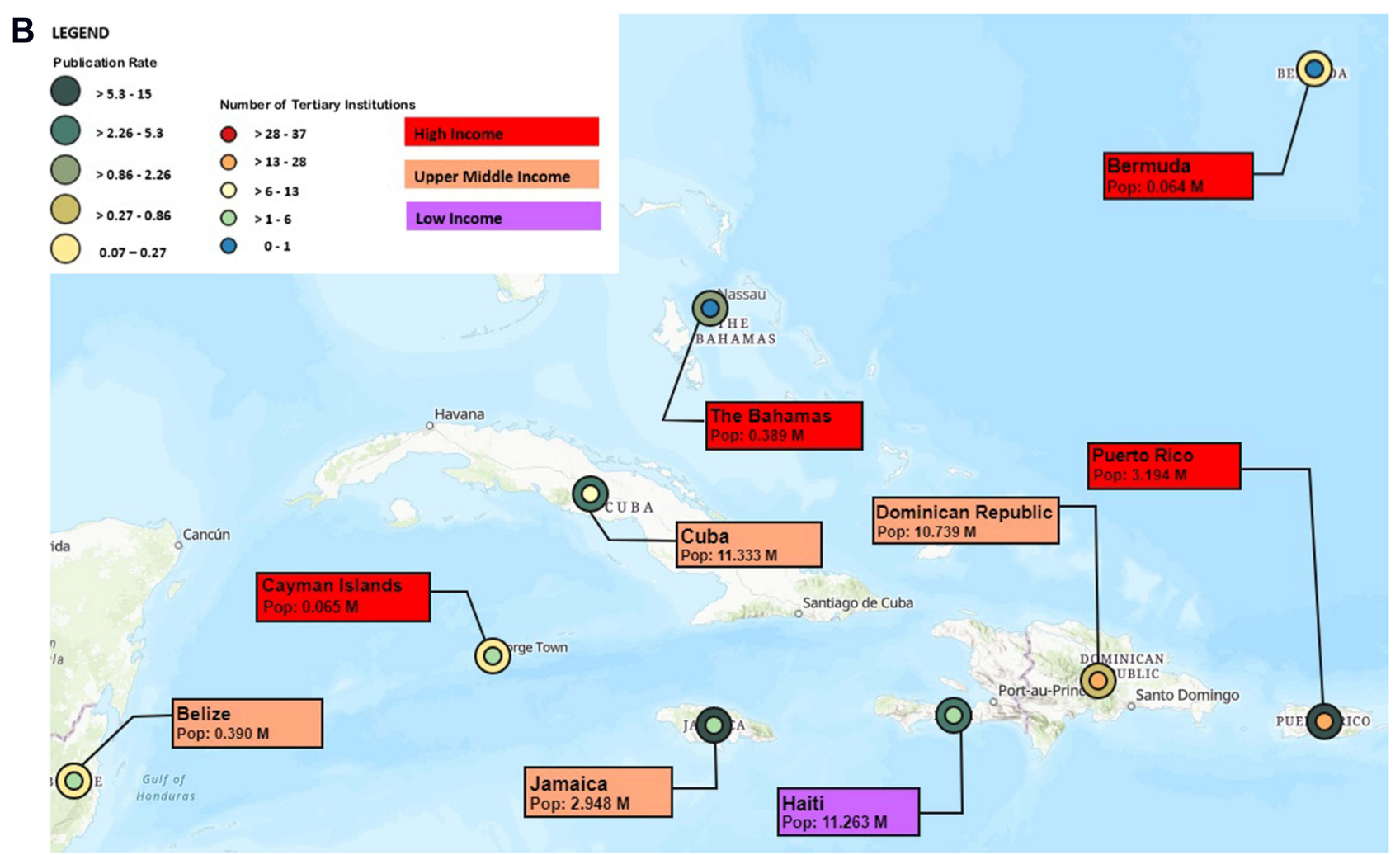

Figure 4 Continued.

institutions - had a 15-year PR that remained relatively steady over time. The Cuban government invests heavily in education, making it free from primary to doctoral level, emphasizing science and medicine. ${ }^{20,21}$ However, the US trade embargo hinders information sharing and may make it difficult to attain resources for research such as grants and equipment. ${ }^{22}$ This long-standing disadvantage may explain the lack of an increase in PR over time. Haiti - a low-income country of 11.26 M people and 6 tertiary education institutions - had a 15-year PR (2.07 papers/year) higher than several high-income countries. Their low-income status has exacerbated inequalities in their education system, which is mostly privatized and prohibitive for much of its population. ${ }^{23}$ Following the privatization of education, we also noted that most publications on their population were linked to foreign universities.

Ideally, a country burdened by a cancer type is obligated to focus resources on research and implement strategies to reduce this cancer burden. Our investigation of whether countries were focusing their research efforts on cancer types that were the top causes of cancer-related deaths revealed some alignment with Trinidad and Tobago and Jamaica, focusing on prostate and breast cancer research as a priority, for example. It is unclear whether any of the governments of the Caribbean region provide incentives to focus local research in line with the disease burden or if there is a clear national research agenda.

\section{Limitations and Future Directions}

In ReCCap development, PubMed was the only database queried; therefore, papers published in journals that are not Medline-indexed would not have been found. In the future, we will expand our search to other databases (eg, Latin America and Caribbean Health Sciences Literature (LILACS)) and some region-specific journals (eg West Indian Medical Journal). Lastly, the database will be updated quarterly to incorporate recent work and is presently hosted on the CCRI website (www.ccrinitiative. com) for use. 


\section{ReCCAP}

\section{Home About}

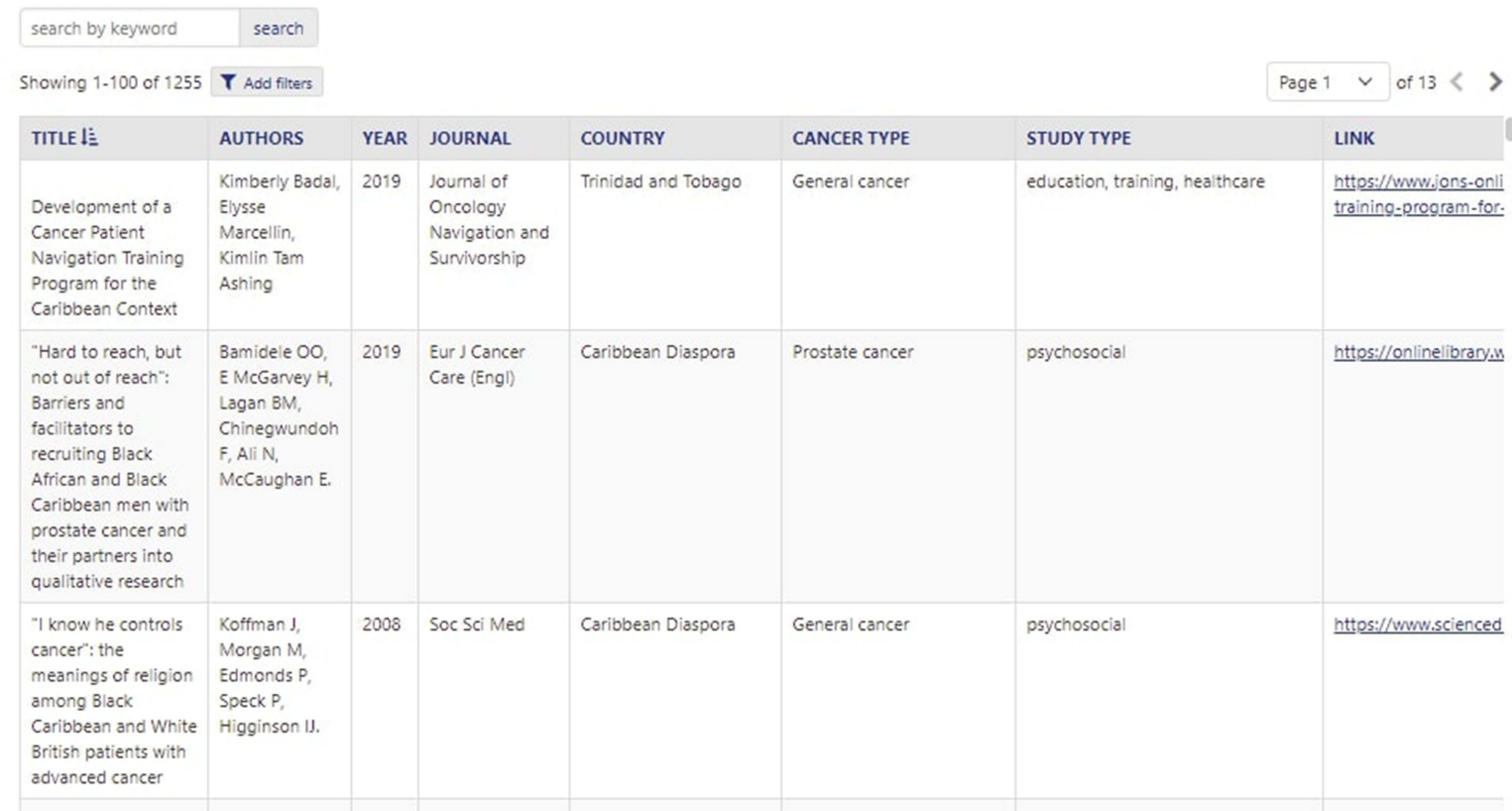

Figure 5 Snapshot of the ReCCaP database interface. Searches can be done with keywords and filters using any of the available fields (title, authors, link, journal, country, cancer type, year and study type).

\section{Conclusion}

$\mathrm{ReCCaP}$ provides an easily searchable database highlighting published work and gaps in knowledge on cancer in the Caribbean and diaspora. It also highlights an overall low cancer PR across the Caribbean region. Population size, education (number of tertiary education institutions), and income may be PR drivers in some territories. More focus on cancer research in the Caribbean region is urgently needed.

\section{Acknowledgments}

We want to thank Ms Jada Clarke for her assistance in editing the maps and Dr Wayne A. Warner for his insights during analysis.

\section{Author Contributions}

All authors contributed to data analysis, drafting or revising the article, have agreed on the journal to which the article will be submitted, gave final approval of the version to be published, and agree to be accountable for all aspects of the work.

\section{Funding}

The Caribbean Cancer Research Initiative funded this study.

\section{Disclosure}

We have no conflicts of interest to disclose.

\section{References}

1. Worldometers.info. Caribbean Population Dover, Delaware, U.S.A.; 2020. Available from: https://www.worldometers.info/worldpopulation/caribbean-population/. Accessed February 1, 2021.

2. Bank TW. The World Bank in the Caribbean Washington, DC. Available from: https://www.worldbank.org/en/country/caribbean/over view\#2. Accessed January 2, 2021.

3. World Health Organisation. Cancer Fact Sheet World Health Organisation; 2018. Available from: https://www.who.int/news-room /fact-sheets/detail/cancer. Accessed October 23, 2020.

4. Ferlay JEM, Lam F, Colombet M, et al. Global Cancer Observatory: cancer Today Lyon. France:: International Agency for Research on Cancer; 2020. Available from: https://gco.iarc.fr/today. Accessed January $31,2021$.

5. Razzaghi H, Quesnel-Crooks S, Sherman R, et al. Leading Causes of Cancer Mortality - Caribbean Region, 2003-2013. MMWR Morb Mortal Wkly Rep. 2016;65(49):1395-1400; PubMed PMID: 27977639. doi: $10.15585 / \mathrm{mmwr} . \mathrm{mm} 6549 \mathrm{a} 3$

6. Ragin C, Banydeen R, Zhang C, et al. Breast Cancer Research in the Caribbean: analysis of Reports From 1975 to 2017. J Glob Oncol. 2018;4:1-21. doi: 10.1200/JGO.18.00044. PubMed PMID: 30481085. PubMed Central PMCID: PMCPMC6818300.

7. McKee M, Stuckler D, Basu S. Where there is no health research: what can be done to fill the global gaps in health research? PLoS Med. 2012;9(4):e1001209. doi: 10.1371/journal.pmed.1001209. PubMed PMID: 22545025. PubMed Central PMCID: PMCPMC3335864. 
8. Barreto SM, Miranda JJ, Figueroa JP, et al. Epidemiology in Latin America and the Caribbean: current situation and challenges. Int $J$ Epidemiol. 2012; 41(2):557-571. doi: 10.1093/ije/dys017. PubMed PMID: 22407860. PubMed Central PMCID: PMCPMC3324459

9. Moloney A. Latin America faces hurdles in health research. Lancet. 2009;374(9695):1053-1054. [PubMed PMID: 19790287]. doi:10.1016/s0140-6736(09)61688-3

10. Tulloch-Reid MK, Saravia NG, Dennis RJ, et al. Strengthening institutional capacity for equitable health research: lessons from Latin America and the Caribbean. BMJ. 2018;362:k2456. doi: 10.1136/bmj.k2456. PubMed PMID: 30012634. PubMed Central PMCID: PMCPMC6046649 interests and have no relevant interests to declare.

11. PAHO/WHO. Report on Strengthening Research Capacities for Health in the Caribbean, 2007-2017; 2017.

12. Ruiz EF, Proano A, Proano D, Torres-Roman JS, Miranda JJ, Latin T. America and the Caribbean search strategy proposal. Glob Health Promot. 2018;25(3):60-64. [PubMed PMID: 27491807]. doi: $10.1177 / 1757975916661089$

13. Team RC. R: a language and environment for statistical computing. Vienna, Austria: R Foundation for Statistical Computing; 2020.

14. Bank TW. World Bank Country and Lending Groups. Available from: https://datahelpdesk.worldbank.org/knowledgebase/articles/906519world-bank-country-and-lending-groups. Accessed December 2016.

15. UniPage. Sydney, Australia. Available from: www.unipage.net. Accessed June 23, 2021.

16. Joachim C, Veronique-Baudin J, Ulric-Gervaise S, et al. Cancer burden in the Caribbean: an overview of the Martinique Cancer Registry profile. BMC Cancer. 2019; 19(1):239. doi: 10.1186/ s12885-019-5434-6. PubMed PMID: 30876409. PubMed Central PMCID: PMCPMC6420743
17. Joachim C, Veronique-Baudin J, Almont T, et al. Cohort profile: the Martinique Cancer Registry and the quality of life prostate cancer cohort (QoL Prostate-MQ): challenges and prospects for reducing disparities in the Caribbean. BMJ Open. 2018; 8(7):e021540. doi: 10.1136/bmjopen-2018-021540. PubMed PMID: 30049695. PubMed Central PMCID: PMCPMC6067331

18. Joachim C, Veronique-Baudin J, Desroziers L, et al. Gynaecological cancer in Caribbean women: data from the French population-based cancer registries of Martinique, Guadeloupe and French Guiana (2007-2014). BMC Cancer. 2020; 20(1):643. doi: 10.1186/s12885020-07128-1. PubMed PMID: 32650744. PubMed Central PMCID: PMCPMC7350571

19. McPherse T. Back in recession - Jamaican economy contracts for third quarter. 2012.

20. Gasperini L. The Cuban Education System: lessons and Dilemmas. Country Studies: education Reform and Management Publication Series. ERIC. 2000;1.

21. Keck CW, Reed GA. The curious case of Cuba. Am J Public Health. 2012;102(8):e13-22. doi: 10.2105/AJPH.2012.300822. PubMed PMID: 22698011. PubMed Central PMCID: PMCPMC3464859.

22. Drain PK, Barry M. Global health. Fifty years of U.S. embargo: cuba's health outcomes and lessons. Science. 2010;328 (5978):572-573. doi: 10.1126/science.1189680. PubMed PMID: 20430999. PubMed Central PMCID: PMCPMC3990013.

23. Bank TW. Four Things You Need to Know About Education in Haiti; 2015. Available from: https://www.worldbank.org/en/news/feature/ 2015/03/12/four-things-you-need-to-know-about-education-in-haiti. Accessed February 1, 2021.

\section{Publish your work in this journal}

Cancer Management and Research is an international, peer-reviewed open access journal focusing on cancer research and the optimal use of preventative and integrated treatment interventions to achieve improved outcomes, enhanced survival and quality of life for the cancer patient.
The manuscript management system is completely online and includes a very quick and fair peer-review system, which is all easy to use. Visit http://www.dovepress.com/testimonials.php to read real quotes from published authors. 